\title{
DIE SKEPPING VAN VADERLANDE IN SUID-AFRIKA
}

\section{INLEIDING.}

Die historiese ontwikkelingsgang van "vaderlande" soos (tans bekend) in Suid-Afrika ten opsigte van die verskillende Bantoe etniese groepe en die Blankes is in hoofsaak gekenmerk deur 'ngraanvanklike onstabiele en vloeibare grenssituasie, gevolg deur pogings om stabiliteit te bewerkstellig en gebiedssoewereiniteit vas te lê vir die toekoms van Suid-Afrika. Gebiedsgrense as synde in juridiese sin die limiete van ' $n$ bepaalde staatsoewereiniteit en -gesag oor persone (onderdane en burgers) is egter nie absoluut nie en daar kan in die Suid-Afrikaanse situasie allermins verwag word dat die stabilisering van grense en gebiedssoewereiniteit die mobiliteit van mense in groter sosiale verbande oor inters uaatlike grense heen sal laat verflou of selfs ophef; dit sal eerder ' $n$ ordening van bewegings oor grense heen (veral tussen die Blank gesentreerde ekonomiese sentra en die verskillende tuislande) tot gevolg hê.

Die begrippe volk, ras, lokasies, reservate, tuislande, vaderlande, konsolidasie van gebiede, vergroting van vaderlande het gelykerwyse! 'n ontwikkeling beleef, maar dit is ook waar dat die begrippe in die Suid-Afrikaanse konteks nog nie almal deurdink en dat die volle implikasies daarvan nog nie besef is nie.

Sonder om te poog om die herkoms en ontstaan van vaderlande in Suid-Afrika (histories gesien) volledig te probeer stel, is dit tog nodig dat sekere aspekte uit die geskiedenis gelig moet word om perspektief te verkry. Die feit is eenvoudig dit dat die meeste van die vraagstukke ten opsigte van grond en grense van vandag bykans sonder uitsondering sy wortels in die geskiedenis van die Suid-Afrikaanse situasie het - erfgoedere van die koloniale era. Die magte en faktore wat hulle merktekens gelaat het kan soos volg in hoofsaak aangeteken word:

Die botsing van Afrikaner en Britse invloede in intensies.

... Kulturele en etniese verskille. (Vgl botsende waardesisteme ten

- opsigte van grondbesit en -benutting tussen die Blankes en die Bantoe etniese groepe.)

Die vestigingspatroon van die Blankes en die Bantoegroepe.

... Militêr-strategiese beleidsrigtings van die imperiale bewind en

... Afrikaner en Britse pragmatiese en gerieflikheidsoorwegings ten opsigte van arbeidsbeskikbaarheid.

Die lifaqana- (vertrooiings-) oorloë tydens die bewind van Tja-

... ka en Dingane, Soshangane en Mantatisi, interne stamkonflikte en opvolgingstwiste. 
Die onvermoë (in bepaalde gevalle) van die destydse Britse im... periale regering en ook van die Afrikanerrepublieke om die vraagstuk ten opsigte van grond en grense te stabiliseer.

\section{VOOR UNIFIKASIE}

\subsection{DIE KAAPKOLONIE.}

Die huidige Ciskei (wes van die Keirivier) was die gebied waar die oosgrensvraagstuk hom uitgewoed het in die aanvanklike fase van kontak tussen Blankes en Xhosa sedert 1752. In 1835 (na die sede Xhosa-oorlog) is die gebied tussen die Keiskamma en die Keiriviere geannekseer deur die Kaapse Goewerneur onder die naam van die "Province of Queen Adelaide" en in "lokasies" verdeel vir bepaalde Xhosastamme. ${ }^{(1)} \mathrm{Bg}$. anneksasie is eter nie deur die Imperiale regering in London gesanksioneer nie en die beleid is pas daarna ontruim. Na die sewende Xhosa-oorlog (1846-1847) is die gebied weer geannekseer onder die naam van Brits Kaffraria en weer in "lokasies" verdeel. Die grense van die gebied is in 1853 uitgebrei om die Glen Grey-distrik in te sluit en ' $n$ "lokasiestelsel" is in die gebied van toepassing gemaak. Die lokasies het nie 'n aaneengeslote gebied gevorm nie en Blankes het reeds voor die inlywing van die gebied by die Kaapkolonie in 1865 hulle in die Ciskei gevestig. (2) Die finale afbakening van lokasies in die Ciskei het in 1878 plaasgevind en die gebiede wat op die manier opsy gestel is vir die bewoning deur Xhosastamme, is in 1913 in die Naturellen Grond Wet opgeneem as ingelyste gebiede vir die uitsluitlike okkupasie en bewoning deur Bantoe.

\subsection{TRANSKEI}

Die gebied strek vanaf die Keirivier in die suide tot aan die suidgrens van Natal en vanaf die Indiese oseaan in die ooste na die Drakensberge in die weste met 'n totale oppervlakte van 4235551 hektaar. Histories val die Transkei in die volgende gebiede uiteen:

\subsubsection{DIE EINTLIKE TRANSKEI}

Bogenoemde gebiede bestaan uit die distrikte Butterworth, Iautywa, Kentani, Nqamakwe, Tsomo en Willowvale en is by die Kaapkolonie ingelyf in 1879 (Nqamakwe en Tsomo), 1883 (Butterworth : Fingogebied) en in 1891 (Kentani en Willowvale: Gcalekagebied) nadat die mag van Sarili (Kreli) verbreek is. ${ }^{(3)}$

\subsubsection{TEMBOLAND}

Temboland bestaan uit Emigrante Temboland (distrikte van St. Marks, Xalanga), eintlike Temboland (Engcobo, Umtata, Mqanduli) en Bomvanaland (Elliotdale). As gevolg van die Tjakabewind het van die Tembu hulle oorspronklike gebiede verlaat en hulle in die Ciskei (Queenstowndistrik) gevestig maar is na die anneksasie van die gebied 
verskuif na die "Tamboekielokasie" wes van die Indwerivier (Glen Grey-/Lady Frere-distrik van die Ciskei). In 1864 is as gevolg van imperiale beleid, 'n deel van die Tembu (bekend as emigrante Tembu) wes van die Indwerivier, hervestig aan die ooste van die rivieroewer. Tembo wat egter nie die Ciskei verlaat het nie, is binne 'n reservaat geplaas in die Glen Greydistrik. Hierdeur is as gevolg van die historiese losmaking tussen die Cis- en Transkei, die Tembo in twee gebiede verdeel met die swartepunt in die Transkei. ${ }^{(4)}$

Die eintlike Temboland is in 1885 saam met Bomvanaland en Emigrante Temboland geannekseer.

\subsubsection{GRIEKWALAND-OOS EN MOUNT AYLIFF:}

Hierdie gebiede omvat die distrikte van Mt. Fletcher, Qumbu, Tsolo, Matatiele, Kokstad (Mt. Currie), Umzimkulu, Mt. Frere en Mt. Ayliff. ${ }^{(5)}$ In 1861 het Faku, die erkende Opperhoof van die Pondo 'n deel van sy gebied tussen die Umtata en Umzimkuluriviere aan die Kaapse regering gesedeer en in 1862 is die Griekwas van Adam Kok vanaf Philippolis in die gebied oos van die Umzimvuburivier (die huidige distrik van Kokstad en Umzimkulu) gevestig. Basotho-oorloë het ook daartoe bygedra dat die Sotho-elemente nadat Nehemia Mosjesj hom aan die bolope van die Umzimvuburivier gevestig het) hulle in die gebied versterk het en aanleiding gegee het tot eise dat die gebied by Lesotho ingeskakel moet word. ${ }^{(6)}$ Die gebied is in 1879 by die Kaapkolonie ingelyf en in 1886 is 'n deel van die Mt. Ayliffgebied (Xesibegebied) by Griekwaland-Oos ingelyf. As gevolg van rebellies in 1880 in Griekwaland-Oos om Blanke gesag omver te werp is in 1883 lokasies vir Bantoe-okkupasie in Blanke gebiede afgesonder. Kokstaddistrik bevat geen Bantoegebied nie en vorm tans nie deel van die Transkeise grondgebied ingevolge die Transkeise Konstitusie nie. ${ }^{(7)}$

\subsubsection{PONDOLAND:}

Die gebied van Faku is in 1894 by die Kaapkolonie ingelyf hoofsaaklik as gevolg vah intriges van Faku self. ${ }^{(8)}$

\subsubsection{PORT ST. JOHNS:}

Die hawe van Port St. Johns plus 'n gedeelte van die binneland aan die westelike oewer van die Umsimvuburivier is in 1878 deur die Britse regering van die hoofkaptein van die Wes-Pondo gekoop en in 1884 geannekseer. ${ }^{(9)}$. 


\subsubsection{BRITS-BETSJOEANALAND:}

(Mafeking, Vryburg, Kuruman, Taung, Gordonia).

Die verdrywing van Mzilikazi in 1837 deur Potgieter met behulp van Tswanatroepe, het gelei tot die verklaring van die deel van Mzilikazigrondgebied as Voortrekkergebied terwyl aan Tswana wat militêre hulp verleen het die Setlagolereserwe en Moloporeserwe toegeken is. ' $\mathrm{n}$ Kommissie het in $\mathbf{1 8 8 5}$ reservate aan die Tswana (as kroongrond) uitgemeet maar as vergelding vir die Langebergrebellie van $1896-1897$ is 'n hele aantal van die reservate tot niet gemaak. naamlik die van Phokwane (Taung), Garaphoane, Dibeng, en Hathu. ${ }^{(10)}$

\subsubsection{GRIEKWALAND-WES:}

(Barkly-Wes, Kimberley, Postmasburg).

In opdrag van 'n kommissie van 1877 is daar in 1883 gebiede vir Bantoe-okkupasie afgesonder en in 1898, na die inlywing van die gebiede is die "lokasies" verklein. Beleid het wel later so geswaai dat bogenoemde "lokasies" as "swartkolle" beskou is en vervang is met vergoedende grond in die Kurumandistrik. (11)

\subsubsection{NATAL:}

Die anneksasie van Natal het die pogings van die Natalse Republiek om die Zoeloe in Natal tussen die Blankes uit te skuif, verydel en die daaropvolgende patroon vir grondreservering het op pragmatiese wyse geskied. Verskeie kommissies is aangewys om aanbevelings ten opsigte van grondbesit te maak. Beperkte plakkery is toegelaat (arbeidsbronne) en "lokasies" is versprei oor die gebied met die oog op arbeidsbeskikbaarheid. Hierbenewens het 19 sendingreservate tot stand gekom tussen $1862-1887$ en is in 1903 oorgedra aan die Natalse Naturelle Trust. (12)

\subsubsection{ZOELOELAND:}

$\mathrm{Na}$ die anneksasie van Zoeloeland in 1897 is 21 reservate afgebaken (1904) en in 1909 oorgedra aan die Zoeloelandse Naturelle Trust.

Die totale oppervlakte van die reservate was 1617179 hekataar. $^{(13)}$

\subsection{ORANJE VRYSTAAT:}

Met die koms van die Voortrekkers was daar slegs twee stamme woonagtig naamlik die Barolong-boo-Seleka van kaptein Moroka te Thabu Nchu en die van kaptein Oetzi te Witsieshoek. Die huidige Thaba Nchu en Selibareservate word deur die Barolong bewoon en Witzieshoek deur die Suidsothostam van kaptein Wessels Mota. ${ }^{(14)}$ 


\subsection{TRANSVAAL:}

'n Lokasiekommissie is in 1853 in die lewe geroep om die grense van die gebiede van die Bantoestamme binne die Z.A.R. te bepaal per verdrag. Laasgenoemde verdrag moes van tyd tot tyd hernu word. Verskeie reservate asook gronde toegestaan aan die sendelinge het in wes-, noord- en noord-oos Transvaal ontstaan. Die toevloei van Bantoe van buite die Z.A.R.-grense het gelei tot plakkery op omliggende plase en 'n verhoogde druk op die beskikbare bestaansbronne. Op aanbeveling van "Den Kafferkommissie" van 1871 het die Volksraad besluit om:

... regeringsreserwes te stig,

... lokasies in distrikte te versprei (arbeid),

... plakkery op Blanke plase te verbied en

... grond wat deur stamme aangekoop is, nie te vervreem nie.

'Tydens 1877-1881 onder Britse bewind, het die grondvraagstuk verder in 'n probleem ontwikkel. In 1881 is 'n permanente Lokasiekommissie op die been gebring in wie se naam privaat- of stamgrond (in gevalle van Bantoe) geregistreer sou word. Tussen 1884 en 1896 is 22 lokasies in Transvaal afgebaken en geregistreer maar alle Bantoe was nog nie gevestig nie. Eers in 1905 kon weer hieraan aandag verleen word. ${ }^{(15)}$ Tydens die bestaan van die Z.A.R. is die Mapochoorlog gevoer waardeur die Ndebele van hulle tradisionele Mapochs Gronden in die distrik Roossenekal verdryf is en op Blanke plase in Pretoria-omgewing ingeboek is. Die Ndebele woon verspreid oor 'Transvaal waarvan sommige onder die Tswana en die NoordSotho gevestig is terwyl een deel naamlik die Suid-Ndebele (Ndzundza van Mapoch) in die Groblersdaldistrik gevestig is. Hierbenewens woon baie Ndebele op Blanke plase op die Oos-Transvaalse hoëveld.

Die totale grondgebied afgesonder as lokasies en reservate voor 1910 vir uitsluitlike Bantoe-okkupasie sien soos volg daar uit:

Kaapprovinsie 5139192 ha 6000000 morge

$\begin{array}{lrr}\text { Natal } & 2569596 & 3000000 \text { morge } \\ \text { O.V.S. } & 64240 & 75000 \text { morge } \\ \text { Transvaal } & 770879 & 900000 \text { morge }\end{array}$

Totaal: $\quad 8543907$ ha 9975000 morge

Die vraag na meer grond en finale grense is reeds voor 1910 te berde gebring toe die Interkoloniale kommissie van 1903-1905 na ondersoek van die situasie verklaar het: ". . . the time has arrived that the lands dedicated and set apart ... as locations, reserves or otherwise, should be defined, delimited and reserved for Natives by legislative enactment; this should be done with a view to finality 
in the $\mathrm{pr}_{\text {- }}$ ision of land for the Native population, and that thereafter no more land should be reserved for the Native cccupation". $\left({ }^{16)}\right.$

\subsection{DIE NATURELLEN GROND WET VAN 1913}

Die benadering van die Interkoloniale Kommissie is beliggaam in die Naturellen Grond Wet van 1913 wat as interim matreël die de facto posisie ten opsigte van grond en grense in Suid-Afrika slegs de jure erken en vasgelê het. Die bestaande Bantoegebiede is omskryf en opgeneem in die bylae van die wet en sou bekendstaan as ingelyste/afgesonderde gebiede en is verskans vir die eksklusiewe okkupasie en besit van die Bantoe etniese groepe.

Die beginsel is in die wet anvaar dat binne die Bantoegebiede (ingelyste/afgesonderde gebiede) geen persoon behalwe 'n Bantoe grond kon bekom nie en vice versa ten opsigte van Blanke gebiede. As gevolg van die destydse geldende Kaapse kiesreg is dié bepaling nie van krag gemaak op die Kaapprovinsie nie omdat dit moontlike Nie-Blanke kiesers kon diskwalifiseer as kiersers indien hulle hulle grond ('n kjesvereiste) buite die ingelyste gebiede moes afstaan. Die praktyk het verder daartoe bygedra dat die huidige Ciskei in ongekonsolideerde vorm bestaan.

Teen 1913 was die beskikbare reservate en lokasies reeds ten volle beset en is die Beaumontkommissie in 1913 aangestel om verder in tegaan op die vraagstuk van meer grond. As gevolg van Blanke openbare mening is die aanbevelings van die kommissie ('n ekstra $6852256 \mathrm{ha}$ ) in 1971 nie aanvaar nie. Hierna is 5 Plaaslike Komitees aangewys om die saak de novo op plaaslike vlak te ondersoek. Ook die aanbevelings van die komitees het vanweë die teenkanting van Blanke openbare mening in die slag gebly terwyl die druk op die bestaande oppervlaktes in die afgesonderde gebiede steeds toegeneem het en gepaard gegaan het met swakker ekonomiese en maatskaplike toestande. Die vraagstuk is egter op administratiewe vlak ietwat verlig toe die Goewerneur-generaal beslis het dat grond wat deur beide die Beaumontkommissie en die 5 Plaaslike Komitees aanbeveel is aangekoop kon word vir Bantoe-okkupasie. Die grootte van die gebiede in 1913 ingelys as Bantoegebiede en as persentasie van die totale oppervlakte van die destydse Unie en sy provinsies sien soos volg daar uit:

\begin{tabular}{|c|c|c|c|}
\hline $\begin{array}{l}\text { Provinsie } \\
\text { Kaap } \\
\text { Tlansvaal }\end{array}$ & $\begin{array}{l}\text { Totale grootte } \\
71691728 \mathrm{ha} \\
83700000 \mathrm{morge} \\
28608168 \mathrm{ha} \\
33400000 \mathrm{morge}\end{array}$ & $\begin{array}{l}\text { Bantoegebied } \\
5325091 \text { ha } \\
6217037 \text { morge } \\
992974 \text { ha } \\
1159296 \text { morge }\end{array}$ & $\begin{array}{c}\text { Persentasie } \\
7,5\end{array}$ \\
\hline
\end{tabular}




$\begin{array}{lrrl}\text { Natal } & 9122065 \text { ha } & 2545880 \mathrm{ha} & \\ & 10650000 \mathrm{morge} & 2972312 \mathrm{morge} & 27,9 \\ \text { O.V.S. } & 12676673 \mathrm{ha} & 63631 \mathrm{ha} & \\ & 14800000 \mathrm{morge} & 74290 \mathrm{morge} & \mathrm{o}, 5 \\ \text { Totale } & 122098636 & 8972406 \mathrm{ha} & \\ & 132550000 \text { morge } & 10422406 \mathrm{morge} & 7,3 \%\end{array}$

Die visie en pogings van genl. J. B. M. Hertzog $(1926,1926,1929)$ en die verslag van die Ekonomiese Naturellekommissie (1930-1932) het hernude aksent geplaas op die vraagstuk van meer grond, oorbevolking en die haglike ekonomiese toestand in die Bantoegebiede. Die uitbreiding van die bestaande gebiede is in 1936 op die Wetboek geplaas as die Naturelle Trust- en Grond Wet ${ }^{(17)}$ waardeur 'n verdere 6209857 ha (7 250000 morge) bekend as oopgestelde gebiede in kwotavorm aan die verskillende provinsies van die Unie toegeken is. Kroongrond in die oopgestelde gebiede en alle bestaande trusts (vergelyk die Umninitrust, Natalse Naturelle Trust ens.) is aan die sentrale Trust oorgedra. Die kwotagrond is soos volg aan die verskillende provinsies toegewys:

\begin{tabular}{lccc} 
Kaap & 1 & 384 & 156 \\
Transvaal & 4 & 306 & 643 \\
O.V.S. & \multicolumn{2}{c}{68523} \\
Natal & 450 & 536
\end{tabular}

Kwotagrond kon in of aanliggend aan (volgens konsolidasie ingelyste of oopgestelde gebiede aangekoop word met geld wat die parlement jaarliks daarvoor sou stem. 'n Totaal van 1284798 ha was onmiddelik besk1kbaar en reeds deur die Bantoe beset terwyl die res (4 $775166 \mathrm{ha}$ ) nog aangekoop moes word deur die regering, individuele Bantoe of Bantoestamme. In 1965 was daar 'n uitstaande balans van ongeveer 1,7 miljoen ha wat nog aangekoop moes word. Die totale oppervlakte van die Bantoegebiede sal volgens die 1936en die 1913 wetgewing op 16,8 miljoen ha te staan kom en nie op 15,0 miljoen ha nie omdat groot dele van die oopgestelde gebiede in 1936 reeds deur Bantoe bewoon was en die volle kwota van 6,2 miljoen ha nie in die oopgestelde gebiede aangekoop kon word nie. In totaal sal die Bantoegebiede $13,7 \%$ van die totale oppervlakte van die R.S.A. beslaan. Die voorsiening wat gemaak is ten opsigte van onteiening van grond en die opruiming van sogenaamde "swartkolle" vir vergoedende grond in die Tuislande was gemik op die konsolidasie van die Tuislande.

'n Oorsig oor die vraagstuk van grond en grense sien die in breë soos volg daar uit: 
... Daadwerklike pogings is aangewend om grond vir die Bantoe te reserveer en te beskerm teen vervreemding.

... Die kern van die huidige gebiede is dié wat tradisioneel deur die Bantoegroepe bewoon is met uitsondering van die Ndebele van Transvaal.

.. Ten tye van die verslag van die Tomlinsonkommissie in $\mathbf{1 9 5 5}$ het die bantoegebiede uit meer as 260 losliggende gebiede bestaan wat in die vrom van 'n perdehoef oor Suid-Afrika gelê het.

... Eventuele staatsgrense en etniese groperinge val in 'n hele aantal gevalle nie saam nie (Vergelyk die Ciskei/Transkei; Suidsotho in die Transkei, Ndebele onder die Pedi en Tswana, heterogene bevolkingstoestande in die Hammanskraalse distrik).

... Hoogs ongekonsolideerde toestande bestaan in Transvaal (Tswana) Zoeloeland, Natal en Ciskei as gevolg van verskei historiese redes.

\subsection{KONSOLIDASIE VAN DIE TUISLANDE:}

Volk en vaderland is twee kante van dieselfde penning. Omdat geen volk/etniese groep bo-aards kan bestaan nie is hy aangewys op die harde werklikheid van ' $n$ territorium met bestaansbronne. Benewens die ekonomiese word 'n psigologiese band tussen volk en grond opgebou wat hom weer op sy beurt laat geld in vorme van patriotisme en nasionalisme. Laasgenoemde verhouding met sy baie sterk psigologies-emosionele karakter is af te lees uit verskeie voorbeelde waar die name van volke en die grondgebied wat deur hulle bewoon word sinoniem geword het. Die afwesigheid van sinonimiteit ten opsigte van die naam van die volk en sy grondgebied beteken egter nie dat daar geen verband bestaan tussen volk en grond nie. Grondgebied is een van die belangrikste bakens waarmee 'n volk hom identifiseer en poog om sy bestaansreg te laat geld. Dit gaan dus in die Suid-Afrikaanse situasie, onder die verantwoordelikheid van die voogregering, om die daarstelling van werklike vaderlande (volkstuistes) en nie om die stigting van blote "reservate" of "lokasies" nie (soos wat die begrip in sy historiese konnotasie bekend is) met die potensiaal om ekonomies, psigologies en juridies 'n ware "Heimat" te wees terwyl dit staatkundig moet kom tot nasionale onafhanklikheid. Bogenoemde impliseer dus minstens die konsolidasie van die bestaande kerngebiede maar ook die uitbreiding van die gebiede .

Vir die daarstelling van vaderlande en die konsolidasie daarvan (dit geld ook die uitbreiding van die gebiede) is die mees algemene norm wat aangelê word die historiese. Dit bly egter gevaarlik om die historiese as absolute norm aan te lê omdat die geskiedenis van die ont- 
staan van die gebiede nie staties was nie. Die vraag kan dus gevra word: watter periode $i_{1}$ die geskiedenis moet as die beslissende en die normatiewe geneem word? (Vergelyk die verskuiwing van die Oosgrens). Die historiese norm sou ook kon impliseer dat vaderlande van die Bantoe etniese groepe nie gekonsolideer hoef te word nie omdat ongekonsolideerdheid juis die resultaat van historiese gebeure is. Dit kan verder inhou dat staatsgrense sonder inagneming van etniese grense bepaal kan word (Balkanisering). Met die historiese as die enigste en absolute norm sou die historiese bekende getwis en gestry oor grond en grense dus slegs maar verder voorgesit word .. getrou aan die trasidisie en geskiedenis van volke, grond en grense.

Min of meer dieselfde geld wanneer die internasionale regsbeginsel ten opsigte van uti possedetis as absolute maatstaf aangelê word. ${ }^{(18)}$ Op grond van die reg van verowering kan van die bestaande grense (vergelyk die Ciskei) so behou word. Oor die kort termyn sou die historiese norm moontlik vir die Blankes voordele ingehou het terwyl dit ten opsigte van die Bantoevolke van Suid-Afrika 'n stempel sou geplaas het op hulle eie historiese verspreidheid en ongekonsolideerdheid van tuislande en vir hulle sowel as die Blankes die wrange toekomsvrugte van grens en korridortwiste verseël het. Omdat die konsolidasie van die Bantoetuislande nie onafhanklik en geisoleerd van die territorium en belange van die Blankes in Suid-Afrika kan geskied nie, kan daar ook nie verwag word dat die uitvoering van konsolidasie ' $n$ eenkanaal werkverrigting moet wees nie.

Dit sou dus in terme van territorium en etniese grense moet impliseer dat "Blanke kolle" en "swartkolle" op een of ander minier opgeklaar moet word. ${ }^{(19)}$ Dit sou verder impliseer, op sterkte van die argument dat die historiese nie as absolute maatstaf aangelê kan word nie, en op sterkte van die historiese lading van grond en grenstwiste en die volkeregeskiedenis, dat daar in Suid-Afrika gepoog moet word om sover as moontlik (veral ten opsigte van grond en grense) die moontlikheid van genoemde wrywings te reduseer deur onder andere die konsolidasie van die Bantoetuislande. Dit sou ook verder impliseer dat die Blanke belange op 'n groter skaal as tot nou "prysgegee" moet word met die oog op langtermyn voordele en die beskerming van langtermyn belange. Die handhawing van die status quo van ongekonsolideerde of halfgekonsolideerde Bantoevaderlande sou op niks anders neerkom as die herskepping van 'n nuwe oosgrensvraagstuk met al sy politieke onstabiliteit nie. Die verdere argument dat daar nêrens in die wêreld voorbeelde bestaan van 'n eenvormige basis of formule waarvolgens grond verdeel word nie, met uitsluiting van die historiese norm van verowering (wat opsigself niks anders is nie as bakens van intervolkse "geregtigheid" en "ongeregtigheid" nie) 
is waar. Die vraag bly egter nog waarom die Suid-Afrikaanse situasie aan die normlose of dan bloot die historiese gebonde moet wees terwyl die geleentheid bestaan om so ver moontlik'n regverdige bedeling met sekuriteite uit te meet? Omdat tyd beskou word as een van die belangrikste faktore waarbinne grense sigself stabiliseer is dit ook waar dat veranderings aan geykte grense baie moeilik tot stand kan kom, sonder om geweld instrumenteel daartoe te maak. Faktore wat in kombinasie as deel van 'n formule ' $n$ rol moet speel vir die konsolidasie van die vaderlande en die vergroting daarvan is die volgende: historiese aansprake, ekonomiese potensiaal, vermoëns van die bevolking om die gebiede te ontwikkel, bevolkingsgetalle, $(20)$ finaliteit oor grond en grense, aaneengeslotenheid van gebiede, strategiese oorwegings (ook vir die Bantoetuislande) en langtermyn interstaatlike verhoudings in Suid-Afrika, die besef dat die voogregering (wat basies die distribuering van grond inisieer en deurvoer) onder 'n baie hoë verantwoordelikheid staan by die uitvoering van sy voog. dyskap. Van die kant van die Blanke moet verder onthou word dat hy sy ona 'hanklikheid en gebiedssoewereiniteit slegs teen 'n bepaalde prys sal behou naamlik onafhanklikheid in 'n kleiner Blanke Suid-Afrik' onder Blanke gesag of 'n onderhorige minderheid in die geheel van die land. ${ }^{(21)}$

Dit sou nodig wees in die Suid-Afrikaanse situasie (om terug te kom na die praktyk) om rekening te hou met die anti-kolonialistiese sentimente wat opgesweep kan word (veral as daar sprekende voorbeelde daarvan bestaan in die praktyk) nadat grense getrek is. Met ander woorde, die eerbaarheid en die regverdigheid van die intensies van die voogregering moet bo alle twyfel gestel word en die bestaande geleenthede daartoe moet benut word terwyl die tyd dit nog toelaat.

Die huidige toestande ten opsigte van die konsolidasie van die Bantoevaderlande sien soos volg daar uit:

\subsection{CISKEI:}

Die aanvanklike 19 gebiede sal tot 5 gekonsolideer word deur die toevoeging van onder andere 185385 ha terwyl nog kwotagrond later bygevoeg kan word. Hoofminister Lennox Sebe van die Ciskei sou hom in 1973 ten gunste van integrering met die Transkei uitgespreek het maar in 1974 weer verklaar het dat die tyd daarvoor nog nie ryp is nie. ${ }^{(2)}$

\subsection{KWA-ZOELOE:}

Die bestaande 188 gebiede sal gekonsolideer word tot 10 nadat die aanvanklike voorstelle van die Departement Bantoeadministrasie en- 
Ontwikkeling om die gebied te konsolideer tot 6 gebiede, deur die Blanke openbare mening afgewys is. ${ }^{23}$ Richardsbaai bly volgens die planne Blanke gebied terwyl Kwa Zoeloe oor die algemeen gekenmerk word deur korridors. 'n Balans van 27000 ha kwotagrond sal nog in die toekoms toegevoeg kan word.

\subsection{GAZANKULU, LEBOWA EN VENDA}

Ingevolge die finale konsolidasieplanne van April 1973 sal Lebowa se bestaande 15 gebiede gekonsolideer word tot 5 . Venda sal van 3 na 2 gebiede gekonsolideer word terwyl 'n $5 \mathrm{~km}$ strook aan die noordgrens (Rhodesiese grens) ontruim sal word vir militêre doeleindes. Die twee gebiede sal in die weste geskei word deur'n strook Gazankulu-gebied.

Die 5 dele waaruit Gazankulu bestaan sal tot 4 gekonsolideer word. Beide die Gazankulu- en Lebowaregerings het die voorstelle verwerp. ${ }^{924}$

\subsection{SWAZI}

Die Nzikazireservaat oos van Nelspruit en Witrivier en die reservaat aan die suidgrens van Swaziland wat Pongola vasdruk tussen Swaziland, Zoeloeland en die Pongolarivier, sal volgens die plan van 1973 uitgesny word en aan die noordwestelike grens van Swaziland gekonsolideer word. ${ }^{(25)}$

\subsection{BOPHUTSWANA:}

Die semi-finale voorstelle van 1972 het beoog om die bestaande 19 gebiede te konsolideer tot 'n maksimum van 6 en 'n minimum van 3 . Bogenoemde saak is egter nog nie afgehandel nie en verdere voorstelle kan in die verband verwag word nadat die Wes-Transvaalse Bantoeadministrasie Streeksraad te kenne gegee het dat dit nie tevrede is met die bestaande voorstelle nie. ${ }^{(26)}$ (Thaba Nchu vorm 'n distrik van Bophuthatswana).

\subsection{STAATS- EN VOLKSGRENSE}

In teenstelling met die res van Afrika waar grense op arbitrêre wyse bepaal is tussen die groot moondhede ter wille van koloniale gebiede in Afrika en waardeur byna geykte en in elke geval baie bekende situasies van "vreemde agressie", indentiteitsbedreiging, rebellies, etniese drukgroepe en separatistebewegings (vergelyk Ruanda, Burundi, Ethiopië, Kenia, Marokko-Mauritani en Spaans Sahara, Soedan, Togo en Ghana, Nigerië ens.) ontstaan het, en steeds daagliks na vore kom, is die Suid-Afrikaanse staats- en volksgrense in 'n redelike mate daarvan vrygestel as gevolg van die etnosentriese benadering tot 
die binnelandse vraagstukke. Die Suid-Afrikaanse situasie is egter nie probleemloos nie want ook in Suid-Afrika val volks- en staatsgrense nie in alle gevalle ooreen nie, met die gevolg dat die moontlikheid ook bestaan vir sesessie in enterne onstabiliteit. Die omvang van die probleem is miskien nie soos in die res van Afrika nie. Voorbeelde van bogenoemde is die Ciskei/Transkei (twee staatstelsels vir dieselfde etniese groep) Suid Sotho in die Transkeise gebied, Lesotho-aansprake op inkorporasie van 'n deel van die Transkei tot sy eie gebied, Swazi in Oos-Transvaal, Tswana oorwig in die Transvaal in vergelyking met Botswana, heterogene etniese toestande in die Hammanskraal se distrik (vergelyk Ndebele) ${ }^{(27)}$ ens. In terme van volksbou en politieke ontwikkeling teen die agiergrond van grense wat etniese groepe prakties verdeel deur korridors is nie een tuisland vry hiervan nie. ${ }^{(28)}$

\subsection{FINALITEIT OOR GRENSE:}

Die voorafgaande pleidooi mag lyk asof dit neerkom op die voort durende sedering van meer grond aan die vaderlande vir die Bantoe etniese groepe. Dit is egter nie die gedagte nie. Finaliteit oor grond en grense is van die grootste belang vir die stabilisering van die grensen grondsituasie.

Grense is kunsmatig, selfs die wat geknoop is aan natuurlike bakens, insoverre as wat dit ' $n$ transendentale en onsigbare uitdrukkings is van gesag- en staatsoewereiniteit. ${ }^{(29)}$ Grense skei mense ook slegs insoverre as wat hulle geskei wil wees. Grense is dus nie absoluut nie maar vind ' $n$ belangrike doelbereiking in die juridiese waardeur die limiete van staatsgesag aangetoon word ter wille van die ordening van die naasbestaan van volkere onder afsonderlike gesagstrukture. Omdat grensaanpassings moeiliker slaag tussen reeds onafhanklike state en op 'n tydstip wanneer grense en grenseise reeds 'n "amptelikheid" verkry het, is dit van baie groot belang dat hier te lande gekom moet word tot finaliteit oor finale grense tussen state. Dit hoef nie noodwendig in te hou dat Blankes byvoorbeeld onmiddelik uit die gesoneerde gebiede hoef pad te gee nie, veral nie in gevalle waar hulle belangrike ontwikkeling stimuleer nie. Die sekuriteit van sulke persone moet egter gewaarborg word terwyl ooreenkomste met die Tuislandregerings gesluit kan word. Finaliteit oor finale grense skyn op hierdie stadium van die Suid-Afrikaanse politiek 'n groot behoefte te wees na beide kante.

\section{J. COETZEE}


1) Van Biljon $P$ Grensbakens tussen Blank en Swart in Suid-Afrika, p $123-128$

2) Maritz C J

Die ontstaan en ontwikkeling van die Bantoetuislande van Suid-Afrika. $\mathrm{P} \mathrm{U}$ vir $\mathrm{C} \mathrm{H} \mathrm{O}, \mathrm{p} 4$.

3) Summary of the report of the commission for the socio-economic development of the Bantu areas within the Union of South Africa. Pretoria Staatsdrukker p 42 en Maritz $C$ J, op cit pp $7-8$.

4) Maritz, Loc Cit.

5) Samevatting van die verslag van die kommissie . ... p 54.

6) Maritz, Op cit p 10

7) Op cit p 10

8) Samevatting van die verslag . . ., op cit p 14,

9) Maritz C J, op cit p 11.

10) Op cit p 13.

11) Samevatting van die verslag .., p 43 en Maritz C J. op cit p 14.

12) Samevatting van die verslag .., p 43.

13) Loc cit.

14) Op cit p 43

15) Op cit, $p 44$ en Maritz C J, p 18-19.-

16) Maritz C J, op cit p 19-20.

17) Sedert die sestigerjare bekend as die S A B T

18) Allot A, BOUNDARIES AND THE LAW IN AFRICA. In Widstrand C S (red). AFRICAN BOUNDARY PROBLEMS. Scandinavian Institute of African Studies, Uppsala 1969 p 17. Die basiese beginsel van bogenoemde was dat die bestaande toestand gehandhaaf moes word afgesien daarvan of die oorsprong wettig was of nie. 'n V V O-besluit van 1964 het lidlande gebind om die bestaande grense (soos tydens onafhanklikheid) te respekteer.

19) Kyk afdeling oor finale grense.

20) Geen rasionele verdeling bestaan, histories gesien, ten opsigte van bevolkingsgetalle en grootte van grondgebied nie en kan dus nie as enigste en absolute maatstaf aangelê word nie. Tog is heelwat oorloë en verhuisings van volke aangeteken as gevolg van die oormatige bevolkingsdruk op die bestaande oppervlakte. Rekening sal in elk geval gehou moet word met bevolkingsaanwas in beplanningsmaatreëls en ook by die toekenning van grond.

21) Coetzee $J \mathrm{H}$, In Suid-Afrikaanse Tuislande, $\mathrm{P} U$ vir $\mathrm{C} \mathrm{HO}$ p 15.

22) Horrel, Muriel: THE AFRICAN HOMELANDS, Institute for Race Relations, Johannesburg 1973 p 15.

23) Op cit pp $20-21$ en Coetzee C J. DIE KONSOLIDASIE VAN DIE BAN IOETUISLANDE EN DIE EISE OM MEER GROND, Woord en daad Augustus 1973 p 15.

24) Vir die aansprake van en die eise deur die regerings van die gebiede kyk Coetzee C J, op cit en Horrel, Muricl op cit pp $29-30$ en To the Point, vol 3(6) p 22.

25) Op cit $\mathrm{p} 30$.

26) Op cit $\mathrm{p} 32-33$.

27) 'n Tuisland is in 1973 aan hulle beloof nadat daar sedert die sestigerjare deur die Ndebele daarop aangedring is om as afsonderlike etniese groep met 'n eie tuisland erken te word en omdat hulle nie onder die Pedi of Tswana wou inskakel nie. Die noord-Ndebele het egter oor die algemeen reeds lankal versotho. 
28) Maritz C J, VOLKSBOU EN POLITIEKE ONTWIKKELING, In SuidAfrikaanse Tuislande. op cit pp 70-71.

29) Allot A, BOUNDARIES AND THE LAW IN AFRICA p 12 In Widstrand C G (red), AFRICAN BOUNDARY PROBLEMS. The Scandinavian Institute of African Studies, Uippsala 1969.

\section{LITERATUUR:}

\section{Coetzee C J}

Die konsolidasie van die Bantoetuislande en die eise om meer grondgebied. Woord en Daad, Augustus 1973.

Coetzee J H

Suid-Afrikaanse Tuislande in die raamwerk van afsonderlike ontwikkeling. In: Suid-Afrikaanse Tuislande, P U vir C H O 1971.

Horrel Muriel

The African Homelands of South Africa, Johannesburg 1973.

Martiz C J

Die ontstaan en ontwikkeling van die Bantoetuislande van Suid-Afrika. P U vir C H O Potchefstroom 1971.

Maritz C J

Volksbou en politieke ontwikkeling. In Suid-Afrikaanse Tuislande. P U vir C H O 1971.

Samevatting van die verslag van die Kommissie vir die sosio-ekonomiese ontwikkeling van die Bantoegebiede binne die Unie van Suid-Afrika. Staatsdrukker Pretoria. U G 61/1955.

To the point. Vol 3(6), Februarie 1974.

Widstrand (red), African boundary problems. Scandinavian Institute for African Studies. Uppsala. 1969. 